\title{
Is human capital protection effective? The case of the Basque Country in
} Spanish Football

\author{
JONATAN CALERO \\ (University of Castilla-La Mancha, Spain) \\ JULIO DEL CORRAL \\ Julio.corral@uclm.es \\ (University of Castilla-La Mancha, Spain)
}

Accepted for publication in Sports, Business and Management: An International Journal.

Cite as: Calero, J. \& del Corral, J. (2014): "Is human capital protection effective? The case of the Basque Country in Spanish football", Sport, Business and Management: An International Journal, Vol. 4 Iss: 3, pp.223 - 236

DOI: http://dx.doi.org/10.1108/SBM-07-2013-0025

This article is (c) Emerald Group Publishing and permission has been granted for this version to appear here (please insert the web address here). Emerald does not grant permission for this article to be further copied/distributed or hosted elsewhere without the express permission from Emerald Group Publishing Limited

\section{Acknowledgments:}

This research has benefited from the Spanish Ministry of Science and Innovation Project ECO2011-29314-C02-02. The authors wish to thank the comments received in the IV Congreso Iberoamericano de Economía del Deporte and PET 2013 and the data received from www.bdfutbol.com. 


\section{ABSTRACT:}

\section{Purpose}

- The purpose of this paper is to analyze whether the protection that some football teams submit to the football players from its region has a positive effect on the quality of the football players from these regions. Particularly, it is analyzed the natural experiment offered by the Basque Country.

\section{Design/methodology/approach}

- First are evaluated the productivity of the regions and thereafter it is analyzed the efficiency of the regions using a production function approach. Lastly, it is evaluated the evolution of the human capital from the under-19 to the absolute national team to determine if the human capital protection of the Basque Country clubs is effective in improving the human capital.

\section{Findings}

- The main finding is that the protection's effect to the productive factors submitted into a competitive environment, exerts a positive influence on the development and growth of this factor, because the protection offers more possibilities of promotion and improving his productive capacity.

\section{Originality/value}

- To the best of knowledge there is no paper that has analyzed the effectiveness of a human capital protection policy. 


\section{Introduction}

In international trade, the infant industry (Krugman and Obstfeld, 2006) argument is used to justify protectionism of certain industries. The essence of the argument is that on many occasions nascent industries do not have the economies of scale to more developed competitors from other countries, and thus they need to be protected until they reach or achieve adequate economies of scale. A similar argument can be used with the aim of protecting the skilled workers in a region by changing economies of scale to skilled human capital, in the sense that a region can protect its human capital until it has reached a similar quality to the human capital of the rest of the world.

The Basque Country can be considered a protectionist region in football, since its two most representative clubs only play with "Basque" footballers as it is the case of the Athletic Club of Bilbao ${ }^{1}$, or with very few players who are not considered "Basques", as it is the case of the Real Sociedad"2. The Spanish league has been organized with a promotion and relegation system. Therefore, if a season the quality of human capital is not good enough to stay in the First Division (i.e., La Liga), it will be doomed to relegation. This allows identifying a protectionism with the special characteristic that is open to competition and therefore it is exerted an incentive to improve the quality of the human capital protected. An additional incentive for the young Basque football players is that they have greater possibilities to belong to the elite against other footballers who are not, as the competence of a Basque footballer who aspire to play in one of the two leading teams in their region, is much smaller than other players which do not belong to this region.

Therefore, Spanish football provides a natural experiment to test if the regions that protect their human capital against the human capital from the rest of the world get greater success in training these workers. If this hypothesis is true it might be extended to other sectors.

The empirical strategy used throughout this paper is to analyze the productivity of the regions skilling their football players. In doing so, they are shown the average products of the regions where the output is the number of professional players and the number of absolute national team players produced by its region and the input is the population. Moreover, it is also estimated a production function at the level of annual autonomous community of professional footballers to determine the efficiency level of the regions in skilling football players. They are used as outputs the number of matches and the minutes played by the players from each region ${ }^{3}$. On the other hand, population, Gross Value Added,

\footnotetext{
${ }^{1}$ Athletic Club Bilbao considers that the players able to play for it are those born in the Basque Country, the French Basque Country and Navarre, such as those players that have Basque ancestors and those who have grown up in the Basque Country. A recent example is that of Fernando Llorente who was born in Logroño (La Rioja), but grew up in the Basque Country.

2 Real Sociedad played with either Basque players or foreign players (non Spanish) until the season 2001-2002. This season Sergio Boris was signed who is a player born in Asturias which marked the end of the policy of not playing with Spanish players who were not from the Basque Country.

${ }^{3}$ It is very common that young players play some minutes in the last match days in which teams could be playing for nothing but pride. To avoid considering these players as output for a region a threshold of 500 minutes in La Liga was used.
} 
the number of professional teams and non-professional teams from each region and its surface are used as inputs.

An effective human capital protection will provide improvements in the skilling of the workers from a region over the age of the workers. In this framework can be determined whether a human capital protection is effective by looking at the evolution of the percentage of players that each region contributes to the National teams from under-19 to the absolute. If the percentage is increasing from U-19 to absolute it will show the effectiveness of the policy. To do this, it was gathered information (i.e., region, matches played in each selection, number of minutes played in each selection) about the players who have represented Spain in U-19, U-20, U-21 and absolute selections from 1985 to 2012.

The rest of the paper is structured in the following way. Next section presents the data and the empirical model. It is followed by the methodology and the results. Finally, some conclusions are drawn.

\section{Data and empirical model}

Two different databases are used. First, a database was built to estimate a production function of football players at the regional level to determine the efficiency level of the regions. To prepare this database the first step was to obtain the name of the players that played in La Liga and the minutes that they played in each season from 1985-1986 to 2011-2012 (nearly 3,500 players). This information was gathered from La Liga official website (www.lfp.es). Thus, it is formed by both national players and foreign players. For the analysis are only required the national players, so the foreign ${ }^{4}$ players were eliminated. In addition players who competed for less than 500 minutes in La Liga throughout his career were also eliminated. In this way, the sample used for the analysis will reduce until reaching a number close to 1,600 players. For each of these players we have obtained some of their personal characteristics (birth placement, autonomous community of training as a player, date of birth, position that plays on the pitch) and data of their sporting career (teams where the player has played, number of seasons playing in first Division, number of minutes played in first Division and number of games played in first Division). These data have been obtained from the following sources: www.bdfutbol.com, Real Federación Española de Fútbol, League of professional football and online encyclopedia Wikipedia. $^{5}$

In addition, different variables have been collected for each of the autonomous communities which are part of Spain, such as the Gross Value Added (GVA), population, surface, the number of teams in the first three categories of Spanish football since the $1985-1986$ season to the present ( $1^{\text {st }}$ Division, $2^{\text {nd }}$ Division A and $2^{\text {nd }}$ Division B) and the number of licenses (only from the year 2012). Both GVA and population have been collected from the BDMORES database from the Ministry of Finance and Public Administration, the surface was gathered from

\footnotetext{
${ }^{4} \mathrm{~A}$ criticism that could be done to the sample, is that do not appear those national players from other top leagues and who have not played in La Liga. However, this fact is relatively new, since until 4 or 5 years ago there were very few players who decide to go outside Spain. Some of the most prominent players that are not in our sample are: Oriol Romeu (Chelsea), Carvajal (Bayern Leverkusen) and Suso (Liverpool).

5 In the appendix is shown a table with descriptive statistics of some of the variables relating to the career of the players.
} 
Wikipedia, the teams of the different categories were obtained in www.futbolme.com and the number of licenses was obtained from the Real Federación Española de Fútbol. In this way, it was created a balanced panel data containing details of each autonomous community between 1985 and 2012.

The production function is estimated using the Cobb-Douglas functional form:

$$
\ln y=\beta_{0}+\sum_{j} \beta_{j} \cdot \ln x_{j}
$$

Where $y$ represents the output, $x$ represents the inputs and $\beta$ are the coefficients to be estimated. In this way, the estimated coefficients reflect inputs output elasticities. Most studies (Bernard and Busse, 2004; Rathke and Woitek, 2007) that have estimated production function of medals or diplomas at the Olympics Games have considered as main inputs the population and income. Similarly in this paper are considered as inputs the population delayed four years and the GVA delayed four years. The main reason for this delay is to maximize the number of observations ${ }^{6}$. The surface was also included as input. The number of licenses of players, coaches and clubs has been incorporated from the year 2012. Given that they were only available for a few years they were incorporated as time invariant variables. In order to control for the number of players, who has each community with a quality close to professional footballers, the ratios of the number of teams in the second and third categories of Spanish football have been included, delayed three years because the players have a training period. These ratios refer to the ratio of the number of teams in the second and third categories by region among the total number of teams in both categories. Lastly, it is included the number of teams in La Liga, because it is expected that a greater number of teams influence positively on the number of players representing each community.

Below is a table of descriptive statistics that shows the dependent variables and independent variables:

\section{INSERT TABLE 1}

Moreover, the website www.bdfutbol.com, provided us a database with players who have participated in any of the Spanish National teams selections U-19, U20, U-21, and absolute between 1985 and 2012. The information that contains this database are the number of matches and the number of minutes played by each player, as well as the tournaments (e.g., U-20 World Cup 2000, absolute European Championship 2008) in which the players have participated and obviously the region of birth of each player. This database is not only used, similarly to the previous one, to analyze the productivity of regions but also and more importantly to analyze the evolution of the number of players that participates in each selection. An increase in the percentage of player from the $\mathrm{U}-19$ to the absolute will show that the human capital from a region improves.

\section{Methodology}

A production function can be defined as the maximum amount of output that can be produced given a certain amount of inputs. Therefore, to estimate a production

\footnotetext{
${ }^{6}$ There is only data of population and VAB until 2008, while we have data of players until 2012.
} 
function consistently with the theoretical definition should be used frontier methods (i.e., stochastic frontier approach or Data Envelopment Analysis). In particular in this paper is used a stochastic frontier model that were proposed by Aigner, Lovell and Schmidt (1977) and Meeusen and van den Broeck (1977) and can be written as:

$$
\ln y=f(x)+\varepsilon ; \varepsilon=v-u ;
$$

where $y$ is the output, $f(x)$ is the representation of technology, $x$ is a vector of inputs, and $\varepsilon$ is a random perturbation composed of two error terms, a symmetrical one, $v$, which reflects the randomness of the production process and statistical noise, whose distribution is a normal with zero mean and variance $\sigma_{v}$; and other asymmetric, $u$, which captures the inefficiency, is non-negative and it is assumed to follow a truncated-normal distribution.

An index for technical efficiency (TE) can be defined as the ratio between the observed output $(y)$ and the maximum possible output $\left(y^{*}\right)$, thus being:

$$
T E_{i}=\frac{y_{i}}{y_{i}^{*}}=\frac{f\left(x_{i} ; \beta\right) \cdot \exp \left(v_{i}-u_{i}\right)}{f\left(x_{i} ; \beta\right) \cdot \exp \left(v_{i}\right)}=\exp \left(-u_{i}\right)
$$

Since $y$ is always less or like $y^{*}$, the TE range is $[0,1]$.

Our data is a balanced panel data and we are interested in obtaining an efficiency indicator for each region. Hence, it is used the Battese and Coelli (1988) model which assumes that the inefficiency of individuals, in this case of regions, is invariant over time:

$$
\operatorname{lny}_{i t}=f\left(x_{i t} ; \beta\right)+\varepsilon_{i t} ; \quad \varepsilon_{i t}=v_{i t}-u_{i}
$$

where $y_{i t}$ is the amount of output obtained, $x_{i t}$ is a vector of inputs, $v_{i t}$ is an independent and identically distributed random perturbation of zero mean and variance $\sigma_{v}^{2}$, and $u_{i}$ is a random perturbation set the truncation to zero from a normal distribution with mean $\mu$ and variance $\sigma_{u}^{2}$, which represents constant over time individual inefficiency. The random variables $v_{i t}$ and $u_{i}$ are considered independent. This model is estimated by maximum likelihood.

To calculate the efficiency of each community is calculated the expectation of $u$ given the different values of $\varepsilon$ gets each community with the following formula:

$$
\begin{gathered}
E\left(u_{i} \mid \varepsilon_{i 1}, \varepsilon_{i 2}, \ldots, \varepsilon_{i T}\right)=\mu_{i}^{*}+\sigma_{*} \cdot\left(\frac{\phi\left(-\mu_{i}^{*} / \sigma_{*}\right)}{1-\Phi\left(-\mu_{i}^{*} / \sigma_{*}\right)}\right) \\
\mu_{i=}^{*}\left(\frac{-\sigma_{u}^{2} \cdot \overline{\varepsilon_{i}}+\left(\mu \cdot \sigma_{v}^{2} / T_{i}\right)}{\sigma^{2}+\left(\sigma_{v}^{2} / T_{i}\right)}\right) \\
\sigma_{*}^{2}=\left(\frac{\sigma_{u}^{2} \cdot \sigma_{v}^{2}}{\sigma_{v}^{2}+\left(T \cdot \sigma_{u}^{2}\right)}\right)
\end{gathered}
$$

where $\phi$ it is the density function and $\Phi$ is the function of a standard normal function. Equation 5 is inserted into equation 3 to calculate the index of TE. 


$$
T E_{i}=\exp \left(-E\left(u_{i} \mid \varepsilon_{i 1}, \varepsilon_{i 2}, \ldots, \varepsilon_{i T}\right)\right)
$$

\section{Results}

This section is formed by three subsections. The first one analyzes the productivity of the regions in the number of players in La Liga and in the absolute national team. The next one analyzes the efficiency of the regions in a production function framework. Finally, the third subsection analyzes the evolution of the human capital from the U-19 to the absolute national team.

\subsection{Productivity of the regions}

The following table shows the number of players in each autonomous community that participated in La Liga, as well as minutes and seasons that have played.

\section{INSERT TABLE 2}

It is shown that the autonomous community that more players have produced during the years in which the analysis focuses is Andalusia, rather logical since it is the most populous of Spain's autonomous community. Second is the Basque Country, this fact can be classified as surprising because it appears in the ranking ahead of other communities, such as the community of Madrid, Catalonia and the Valencia, communities that exceed it by far in terms of number of population, and which should therefore produce a larger number of players than those less populated. But not only appears the Basque Country in second place in the ranking of players, but it also appears both leading the ranking of seasons played by his players as the ranking of minutes played by their players, thus beating Andalusia. That is, despite having been less players in the Basque Country than in Andalusia, the protection which Basque players are submitted, has allowed that they are played more seasons and more minutes in La Liga.

Below is shown a figure that reflects the ratio between the number of players and population, which is aimed at obtaining the average productivity of professional players per population in each of the autonomous communities.

\section{INSERT FIGURE 1}

Only two autonomous communities exceed the $0.01 \%$, the first one and which therefore leads the ranking is Navarre, with a very small population (close to 600,000 inhabitants) gets to bring a large number of players to the First Division of the Spanish football. In second place appears the Basque Country, since as Navarre over one of every 100,000 inhabitants becomes professional, as with a population slightly more than 2 million, provide 221 professional players.

Next figure is similar to the previous one but analyzing the productivity of the regions as the ratio of the number of players in the absolute national team and the population in 2012.

\section{INSERT FIGURE 2}

It can be seen that the most productive region is Navarre followed by the Basque Country. They are followed by Asturias and La Rioja which also have performed in some sense a protective human capital policy especially Asturias. It is 
important to note that all those regions are from the North. From both figures can be concluded that the Basque Country is a very productive community and that the protection which submits to his players is reflected in these results.

\subsection{Efficiency of the regions}

The following table shows the estimates when the dependent variable is the number of minutes. There have been estimated alternative specifications to test the robustness of the results.

\section{INSERT TABLE 3}

It is important to note that all the coefficients are positive in all models, but the ratio of teams of the third division which is negative. It can be seen that the number of teams in La Liga has a positive and significant coefficient in all estimated models, and together with the population that is significant in two of the four models, they are the only ones that have been used for the estimation of the four models. On the other hand the surface has been used for two models being significant to $99 \%$ in two, while the variable clubs licensed has been used in two models and is meaningful to $99 \%$ in one of them. GVA has been used to estimate the first model, being significant at the $99 \%$.

The following table shows the ranking of TE of the autonomous communities in relation to the number of minutes played by their players for each of the estimated models.

\section{INSERT TABLE 4}

Regardless the specification the Basque Country is the most efficient autonomous community. It also appears in the first places Asturias, which is a region as explained above that also carried out a policy of playing with the quarry. As antithesis to these two regions, communities are found with a similar population, but that very lagging position in the ranking, such as Castille-Leon and Galicia, communities whose contribution of players is rather less what should presumably be.

The following table shows the estimation of the models used as dependent variable the number of matches played by the players from each community.

\section{INSERT TABLE 5}

The estimates are similar to those obtained using the number of minutes. Next table shows the communities' efficiency when the number of matches are used the dependent variable.

\section{INSERT TABLE 6}

It is shown that the Basque Country is the autonomous community most efficient, occupying the first position in the ranking on all models estimated but model 3 , where the community most efficient is Navarre; community that is among the first four in all estimated models. This table can be considered to be similar to the previous one, since the results that exposes are practically equal to the table above, the minutes and the matches are related, so if a community players have played many minutes in the first Division, is due to because they have also played a large number of parties.

\subsection{Evolution of the human capital of the regions}


So far it was obtained that the Basque Country and Navarre are the most productive regions in Spain. But which are the reason behind these results? A possible explanation could be that football is more important in these regions than in the other ones, but football is the main sport in all Spanish regions so this explanation does not make much sense. Other possible explanation could be about genetic but this explanation also seems to be very unlikely. Other one could be related with the quality of the coaches so that the better the coaches the better players. But if this explanation is true these regions should be the most productive since the beginning ages. On the other hand, the protection of its human capital could be effective in the sense that induces to improvements in their human capital. By simply analyzing the evolution of the number of players in the national teams from the under-19 to the absolute team can be tested which hypothesis is more likely. Moreover, it can be seen the number of players in the under-19 national team as a proxy of the number of talents from each region, looking at the ratio between the number of players in La Liga and those values can be obtained how have been evolved the human capital of each region. If the ratio is higher for those regions that use a protective human capital policy can be understood as that the protective policy is effective.

The following table shows the number and the percentage of players from each region that have been invited with the different national teams, as well as the number and percentage of matches that these players have played with them.

\section{INSERT TABLE 7}

The table shows that Catalonia, Madrid and Andalusia are the communities autonomous that more players contribute to the under-19 national team, while the Basque Country remains far behind them. With respect to the under-20, Catalonia is the undisputed leader as the $16.97 \%$ players representing this selection come from Catalonia. In this selection begins to observe the leap of the Basque Country, since some of the clubs in this community offer a greater number of possibilities to their young players, allowing some of them to settle in first division at very early ages. In the under-21 the Basque Country is the leader region. While the difference is short, it is still interesting that a community whose population is close to two millions (Spain is close to 45 million of inhabitants), gets to contribute more players than the communities most populated of Spain (i.e., Andalusia, Catalonia, Madrid). Finally, the Basque Country returns to lead the ranking of players contribution, in the senior team.

Therefore, it can be concluded that the Basque Country players are increasing their quality with their age, since the percentage of players is significantly increasing. Similarly to the Basque Country, is observed that Asturias also has an increasing tendency in the number of players in the selections. Moreover, the increase is not such important than the Basque Country and Asturias but Navarre also has an increasing tendency in the number of players. On the other hand, Catalonia has a decreasing tendency.

Lastly, it is analyzed the evolution of the productivity by regions from the u-19 selection up to the senior team. This analysis is based on two ratios that compares the number of players in La Liga and the number of players in the senior team with the number of players from the $u-19$.

INSERT TABLE 8 
These ratios explain the evolution of the human capital of each community. The Basque Country occupies the fifth and fourth place respectively in the rankings. The Basque Country is overcome only by Cantabria, Extremadura and La Rioja, much smaller communities so these ratios must be read cautiously for them. Moreover, Asturias also outperforms the Basque Country, because this community has also performed a human capital protection policy.

\section{CONCLUSIONS}

This paper examines whether the protection that some clubs submit their players has a positive effect on the quality of them. The Basque Country is used because it provides a natural experiment, since most of the teams in the region play with Basque players. In doing so, there have been analyzed the productivity of the regions in the number of La Liga and National team players, the efficiency of the regions and the evolution of the human capital from the U-19 to the absolute national team.

With regard to the participation of players in La Liga, is observed that the Basque Country, being an autonomous community which does not have much population, gets to be the second Community autonomous more players contributed, beating much more populated communities such as the community of Madrid and Catalonia. In addition, communities with a population similar to the Basque Country as Castille-Leon and Castille-La Mancha, appear very lagging positions in the ranking. Moreover, the leader is Navarre which is a region where the players are also protected by the Basque clubs. The same result is found when analyzing the number of players in the absolute national team. These results can be partially due to the number of teams in La Liga from these regions, hence they are estimated several production functions to calculate the efficiency of the regions controlling for different factors. The results show that the Basque Country is the region most efficient in 7 out of 8 production functions estimated whereas Navarre is also well ranked in all models. Therefore, can be concluded that Navarre and the Basque Country are the most productive and efficient regions from Spain.

Analyzing the number of players in the different national teams from $u-19$ to absolute it is found that the Basque Country shows a clear positive tendency. It is in the $u-21$ selection where the protection that the Basque clubs offer their players begins to bear fruit, because the call of Basque players in this selection is triggered. One of the main reasons is that the majority of players who are called upon by the under-21 selection already are players who are part of first Division teams, this fact is differential already that some of the Basque Country clubs offer a greater number of possibilities to their young players, allowing some of them to settle in first Division at very early ages. This is favorable for the Basques, because that will always be more attractive a player who plays in the first Division to another playing in a lower category. This protection is maintained in the senior team, where the Basque Country leads the ranking of players contribution. Therefore, it can be concluded that protection which Basque players are subject is reflected from the under-21 selection, i.e. that there is a favorable evolution of the quality of the Basque players because of the protection that has undergone them during your training period as football players.

Thus, it is found that a human capital protection policy is effective in the sense that allows to improvements in the protected human capital. 


\section{BIBLIOGRAPHY}

Aigner, D., Lovell, C., and Schmidt, P. (1977). Formulation and estimation of stochastic frontier production function models. Journal of Econometrics, 6 , 21-37.

Battese, G., and Coelli, T. (1988). Prediction of firm-level technical efficiencies with a generalized frontier production function and panel data. Journal of Econometrics, 38, 387-399.

Bernard, A., and Busse, M. (2004). Who wins the Olympic Games: Economic resources and medal totals. Review of Economics and Statistics, 86(February), 413-417.

Krugman, P. R., and Obstfeld, M. (2006). Economía internacional Teoría y política (7th ed.). Madrid: Pearson.

Kumbhakar, S., and Lovell, C. K. (2000). Stochastic frontier analysis (1st ed.). Cambridge: Cambridge University Press.

Meeusen, W., and Van Den Broeck, J. (1977). Efficiency estimation from cobbdouglas production functions with composed error. International Economic Review, 18(2), 435-444.

Rathke, A., and Woitek, U. (2007). Economics and the Summer Olympics: An Efficiency Analysis. Journal of Sports Economics, 9(5), 520-537. 
Table 1. Descriptive statistics

\begin{tabular}{lcccc}
\hline Variables & Mean & Typical Deviation & Minimum & Maximum \\
\hline Minutes $(\mathrm{n})$ & 25,978 & 24,109 & 1 & 114,862 \\
Matches $(\mathrm{n})$ & 354 & 327 & 1 & 1,520 \\
Teams in La Liga $(\mathrm{n})$ & 1.054 & 1.027 & 0.001 & 5.001 \\
Population [-4] (inhabitants) & $2,126,472$ & $2,069,188$ & 59,544 & $8,202,220$ \\
Ratio teams Third Division [-3] $(\%)$ & 0.054 & 0.044 & 0.001 & 0.212 \\
GVA [-4] (€ 2000) & $26,383,896$ & $28,744,760$ & 623,266 & $134,395,280$ \\
Licenses of players (n) & 7,079 & 6,031 & 289 & 21,521 \\
Licenses of coaches (n) & 805 & 1,145 & 50 & 5,351 \\
Ratio teams Second Division [-3] (\%) & 0.054 & 0.061 & 0.001 & 0.365 \\
Teams with licensing (n) & 642 & 574 & 37 & 2,120 \\
Surface (km²) & 26,631 & 29,451 & 13 & 94,225 \\
Number of observations & \multicolumn{2}{c}{513} \\
\hline
\end{tabular}

Note: Those minimums that are 0.001 actually are 0 , and those which are 1 are 0 , but in order to estimate a Cobb-Douglas production function it is needed to take logarithms, and since the logarithm of zero does not exist should be prevented this problem by giving a small positive value. 
Table 2. Participation of players in La Liga

\begin{tabular}{lccc}
\hline Regions & Players & Seasons & Minutes \\
\hline Andalusia & 247 & 1,293 & $2,024,899$ \\
Basque Country & 221 & 1,415 & $2,269,830$ \\
Madrid & 183 & 1,021 & $1,672,637$ \\
Catalonia & 176 & 947 & $1,423,733$ \\
Valencia & 118 & 640 & $1,042,005$ \\
Asturias & 101 & 624 & 969,504 \\
Navarre & 77 & 497 & 858,419 \\
Galicia & 69 & 349 & 545,761 \\
Canary Islands & 68 & 330 & 526,958 \\
Castille-Leon & 67 & 405 & 648,148 \\
Cantabria & 55 & 309 & 475,632 \\
Castille-La Mancha & 46 & 258 & 430,666 \\
Balearic Islands & 38 & 207 & 311,249 \\
Aragon & 37 & 245 & 361,270 \\
Extremadura & 36 & 216 & 377,634 \\
La Rioja & 21 & 161 & 253,492 \\
Murcia & 21 & 113 & 187,658 \\
Ceuta & 3 & 17 & 29,189 \\
Melilla & 1 & 7 & 17,404 \\
\hline Total & 1,585 & 9,054 & $14,426,088$ \\
\hline
\end{tabular}

Notes: There were only considered players who played more than 500 minutes in La Liga.

The table has been sorted from highest to lowest depending on the number of professional players produced by each autonomous community since the 1985-1986 season until the 20112012 season. 
Table 3. Parameter estimates of the production function. Dependent variable: Minutes

${ }^{*} p<0.10,{ }^{* *} p<0.05,{ }^{* * *} p<0.01$ 
Table 4. Technical efficiency of regions. Dependent variable: Minutes.

\begin{tabular}{lcccc}
\hline Regions & Model 1 & Model 2 & Model 3 & Model 4 \\
\hline Andalusia & $0.07(17)$ & $0.72(4)$ & $0.61(5)$ & $0.08(12)$ \\
Aragon & $0.18(13)$ & $0.25(16)$ & $0.16(17)$ & $0.03(17)$ \\
Asturias & $0.76(2)$ & $0.79(3)$ & $0.78(3)$ & $0.34(3)$ \\
Balearic Islands & $0.40(9)$ & $0.32(14)$ & $0.31(13)$ & $0.23(8)$ \\
Basque Country & $\mathbf{0 . 8 8 ( 1 )}$ & $\mathbf{0 . 9 0 ( 1 )}$ & $\mathbf{0 . 9 0 ( 1 )}$ & $\mathbf{0 . 7 7 ( 1 )}$ \\
Canary Islands & $0.46(8)$ & $0.45(11)$ & $0.38(11)$ & $0.26(7)$ \\
Cantabria & $0.67(6)$ & $0.46(10)$ & $0.46(9)$ & $0.27(5)$ \\
Castille-La Mancha & $0.75(3)$ & $0.42(12)$ & $0.26(15)$ & $0.03(16)$ \\
Castille-León & $0.03(19)$ & $0.34(13)$ & $0.35(12)$ & $0.03(18)$ \\
Catalonia & $0.16(14)$ & $0.58(6)$ & $0.54(6)$ & $0.14(10)$ \\
Ceuta & $0.36(10)$ & $0.00(18)$ & $0.00(18)$ & $0.08(11)$ \\
Extremadura & $0.27(11)$ & $0.49(9)$ & $0.43(10)$ & $0.06(15)$ \\
Galicia & $0.08(16)$ & $0.30(15)$ & $0.27(14)$ & $0.06(14)$ \\
La Rioja & $0.73(4)$ & $0.49(8)$ & $0.52(7)$ & $0.26(6)$ \\
Madrid & $0.69(5)$ & $0.69(5)$ & $0.72(4)$ & $0.50(2)$ \\
Melilla & $0.07(18)$ & $0.00(19)$ & $0.00(19)$ & $0.02(19)$ \\
Murcia & $0.11(15)$ & $0.18(17)$ & $0.18(16)$ & $0.07(13)$ \\
Navarre & $0.60(7)$ & $0.81(2)$ & $0.81(2)$ & $0.31(4)$ \\
Valencia & $0.18(12)$ & $0.49(7)$ & $0.48(8)$ & $0.14(9)$ \\
\hline
\end{tabular}

Note: In parentheses the ranking each community occupies. 
Table 5. Parameter estimates of the production function. Dependent variable: Matches.

\begin{tabular}{lcccc}
\hline & Model 1 & Model 2 & Model 3 & Model 4 \\
\cline { 2 - 5 } Constant & $-4.519^{*}$ & -1.038 & -0.434 & -1.705 \\
Teams in La Liga (n) & $0.082^{* * *}$ & $0.087^{* * *}$ & $0.086^{* * *}$ & $0.086^{* * *}$ \\
Population [-4] (inhabitants) & $1.044^{* *}$ & $0.539^{* * *}$ & 0.313 & $0.364^{*}$ \\
Ratio teams Third Division [-3] (\%) & -0.009 & & & -0.018 \\
GVA [-4] ( $€$ 2000) & $0.436^{* * *}$ & & & \\
Licenses of players (n) & 0.458 & & & \\
Licenses of coaches (n) & 0.440 & & & \\
Ratio teams Second Division [-3] (\%) & 0.010 & & & 0.009 \\
Teams with licensing (n) & $1.020^{* * *}$ & & 0.452 & \\
Surface $\left(\mathrm{km}{ }^{2}\right)$ & $0.332^{* * *}$ & & & $0.375^{* * *}$ \\
$\sigma$ & 0.005 & 1.356 & 0.729 & -0.224 \\
$\gamma=\sigma_{u}^{2} /\left(\sigma_{u}^{2}+\sigma_{v}^{2}\right)$ & 0.800 & 2.410 & $1.709^{*}$ & 0.416 \\
$\mu$ & 0.715 & -1.119 & 0.625 & $1.449^{* * *}$ \\
Log Likelihood & -462 & -473 & -473 & -468 \\
Number of observations & 513 & 513 & 513 & 513 \\
\hline${ }^{*} \mathrm{p}<0.10,{ }^{* *} \mathrm{p}<0.05,{ }^{* * *} \mathrm{p}<0.01$ & & & &
\end{tabular}


Table 6. Technical efficiency of regions. Dependent variable: Matches.

\begin{tabular}{lcccc}
\hline Regions & Model 1 & Model 2 & Model 3 & Model 4 \\
\hline Andalusia & $0.22(15)$ & $0.49(5)$ & $0.30(9)$ & $0.21(11)$ \\
Aragon & $0.33(12)$ & $0.24(15)$ & $0.13(17)$ & $0.10(17)$ \\
Asturias & $0.81(2)$ & $0.79(3)$ & $0.74(3)$ & $0.52(3)$ \\
Balearic Islands & $0.37(10)$ & $0.33(13)$ & $0.30(8)$ & $0.27(8)$ \\
Basque Country & $\mathbf{0 . 9 1 ( 1 )}$ & $\mathbf{0 . 9 2 ( 1 )}$ & $\mathbf{0 . 8 8 ( 2 )}$ & $\mathbf{0 . 8 4 ( 1 )}$ \\
Canary Islands & $0.45(8)$ & $0.39(10)$ & $0.29(10)$ & $0.31(7)$ \\
Cantabria & $0.58(6)$ & $0.49(6)$ & $0.52(5)$ & $0.36(6)$ \\
Castille-La Mancha & $0.79(3)$ & $0.34(12)$ & $0.16(16)$ & $0.12(15)$ \\
Castille-Leon & $0.11(19)$ & $0.28(14)$ & $0.25(13)$ & $0.10(18)$ \\
Catalonia & $0.27(13)$ & $0.40(9)$ & $0.28(12)$ & $0.24(9)$ \\
Ceuta & $0.37(11)$ & $0.04(18)$ & $0.05(18)$ & $0.18(12)$ \\
Extremadura & $0.42(9)$ & $0.44(8)$ & $0.35(7)$ & $0.17(13)$ \\
Galicia & $0.15(17)$ & $0.23(16)$ & $0.18(14)$ & $0.13(14)$ \\
La Rioja & $0.68(5)$ & $0.60(4)$ & $0.71(4)$ & $0.40(5)$ \\
Madrid & $0.53(7)$ & $0.49(7)$ & $0.44(6)$ & $0.47(4)$ \\
Melilla & $0.18(16)$ & $0.02(19)$ & $0.02(19)$ & $0.09(19)$ \\
Murcia & $0.14(18)$ & $0.17(17)$ & $0.17(15)$ & $0.11(16)$ \\
Navarre & $0.79(4)$ & $0.88(2)$ & $0.89(1)$ & $0.54(2)$ \\
Valencia & $0.26(14)$ & $0.35(11)$ & $0.29(11)$ & $0.22(10)$ \\
\hline
\end{tabular}

Note: The ranking that each community is in parentheses. 
Table 7. Number and percentage of players and matches per selection

\begin{tabular}{|c|c|c|c|c|c|c|c|c|c|c|c|c|c|c|c|c|}
\hline \multirow[b]{3}{*}{ Regions } & \multicolumn{4}{|c|}{ Under-19 } & \multicolumn{4}{|c|}{ Under-20 } & \multicolumn{4}{|c|}{ Under-21 } & \multicolumn{4}{|c|}{ Absolute } \\
\hline & \multicolumn{2}{|c|}{ Players } & \multicolumn{2}{|c|}{ Matches } & \multicolumn{2}{|c|}{ Players } & \multicolumn{2}{|c|}{ Matches } & \multicolumn{2}{|c|}{ Players } & \multicolumn{2}{|c|}{ Matches } & \multicolumn{2}{|c|}{ Players } & \multicolumn{2}{|c|}{ Matches } \\
\hline & $\mathrm{N}$ & $\%$ & $\mathrm{~N}$ & $\%$ & $\mathrm{~N}$ & $\%$ & $\mathrm{~N}$ & $\%$ & $\mathrm{~N}$ & $\%$ & $\mathrm{~N}$ & $\%$ & $\mathrm{~N}$ & $\%$ & $\mathrm{~N}$ & $\%$ \\
\hline Andalusia & 63 & $14.72 \%$ & 292 & $14.74 \%$ & 45 & $11.75 \%$ & 170 & $12.71 \%$ & 87 & $14.24 \%$ & 396 & $11.96 \%$ & 34 & $12.06 \%$ & 553 & $11.09 \%$ \\
\hline Aragon & 11 & $2.57 \%$ & 42 & $2.12 \%$ & 10 & $2.61 \%$ & 37 & $2.77 \%$ & 14 & $2.29 \%$ & 60 & $1.81 \%$ & 7 & $2.48 \%$ & 50 & $1.00 \%$ \\
\hline Asturias & 18 & $4.21 \%$ & 43 & $2.17 \%$ & 20 & $5.22 \%$ & 76 & $5.68 \%$ & 36 & $5.89 \%$ & 200 & $6.04 \%$ & 19 & $6.74 \%$ & 361 & $7.24 \%$ \\
\hline Baleares & 16 & $3.74 \%$ & 78 & $3.94 \%$ & 11 & $2.87 \%$ & 34 & $2.54 \%$ & 10 & $1.64 \%$ & 79 & $2.39 \%$ & 3 & $1.06 \%$ & 88 & $1.77 \%$ \\
\hline Basque Countr. & 42 & $9.81 \%$ & 181 & $9.14 \%$ & 39 & $10.18 \%$ & 131 & $9.79 \%$ & 88 & $14.40 \%$ & 447 & $13.50 \%$ & 43 & $15.25 \%$ & 881 & $17.67 \%$ \\
\hline Canarias & 16 & $3.74 \%$ & 62 & $3.13 \%$ & 15 & $3.92 \%$ & 32 & $2.39 \%$ & 23 & $3.76 \%$ & 121 & $3.66 \%$ & 10 & $3.55 \%$ & 188 & $3.77 \%$ \\
\hline Cantabria & 6 & $1.40 \%$ & 22 & $1.11 \%$ & 11 & $2.87 \%$ & 43 & $3.21 \%$ & 17 & $2.78 \%$ & 65 & $1.96 \%$ & 6 & $2.13 \%$ & 148 & $2.97 \%$ \\
\hline Catalonia & 71 & $16.59 \%$ & 365 & $18.43 \%$ & 65 & $16.97 \%$ & 233 & $17.41 \%$ & 81 & $13.26 \%$ & 473 & $14.29 \%$ & 31 & $10.99 \%$ & 638 & $12.80 \%$ \\
\hline Ceuta & 2 & $0.47 \%$ & 2 & $0.10 \%$ & 2 & $0.52 \%$ & 8 & $0.60 \%$ & 1 & $0.16 \%$ & 1 & $0.03 \%$ & 1 & $0.35 \%$ & 31 & $0.62 \%$ \\
\hline C-La Mancha & 17 & $3.97 \%$ & 74 & $3.74 \%$ & 15 & $3.92 \%$ & 49 & $3.66 \%$ & 18 & $2.95 \%$ & 153 & $4.62 \%$ & 7 & $2.48 \%$ & 152 & $3.05 \%$ \\
\hline C-Leon & 16 & $3.74 \%$ & 80 & $4.04 \%$ & 14 & $3.66 \%$ & 42 & $3.14 \%$ & 35 & $5.73 \%$ & 170 & $5.14 \%$ & 11 & $3.90 \%$ & 140 & $2.81 \%$ \\
\hline Extremadura & 4 & $0.93 \%$ & 17 & $0.86 \%$ & 4 & $1.04 \%$ & 15 & $1.12 \%$ & 9 & $1.47 \%$ & 47 & $1.42 \%$ & 10 & $3.55 \%$ & 135 & $2.71 \%$ \\
\hline Galicia & 15 & $3.50 \%$ & 80 & $4.04 \%$ & 21 & $5.48 \%$ & 75 & $5.61 \%$ & 27 & $4.42 \%$ & 109 & $3.29 \%$ & 10 & $3.55 \%$ & 112 & $2.25 \%$ \\
\hline La Rioja & 3 & $0.70 \%$ & 22 & $1.11 \%$ & 4 & $1.04 \%$ & 12 & $0.90 \%$ & 8 & $1.31 \%$ & 46 & $1.39 \%$ & 5 & $1.77 \%$ & 17 & $0.34 \%$ \\
\hline Madrid & 61 & $14.25 \%$ & 279 & $14.08 \%$ & 42 & $10.97 \%$ & 150 & $11.21 \%$ & 81 & $13.26 \%$ & 475 & $14.35 \%$ & 36 & $12.77 \%$ & 862 & $17.29 \%$ \\
\hline Murcia & 7 & $1.64 \%$ & 40 & $2.02 \%$ & 11 & $2.87 \%$ & 32 & $2.39 \%$ & 11 & $1.80 \%$ & 57 & $1.72 \%$ & 6 & $2.13 \%$ & 111 & $2.23 \%$ \\
\hline Navarre & 18 & $4.21 \%$ & 100 & $5.05 \%$ & 22 & $5.74 \%$ & 87 & $6.50 \%$ & 26 & $4.26 \%$ & 218 & $6.59 \%$ & 15 & $5.32 \%$ & 146 & $2.93 \%$ \\
\hline Valencia & 40 & $9.35 \%$ & 196 & $9.89 \%$ & 31 & $8.09 \%$ & 108 & $8.07 \%$ & 39 & $6.38 \%$ & 193 & $5.83 \%$ & 28 & $9.93 \%$ & 372 & $7.46 \%$ \\
\hline Total & 428 & $100 \%$ & 1,981 & $100 \%$ & 383 & $100 \%$ & 1,338 & $100 \%$ & 611 & $100 \%$ & 3,310 & $100 \%$ & 282 & $100 \%$ & 4,985 & $100 \%$ \\
\hline
\end{tabular}

Notes: Melilla has been eliminated since has never contributed any player to any of the selections.

Unofficial names of the autonomous communities due to lack of space. 
Table 8. Evolution of the human capital

\begin{tabular}{lccccc}
\hline Regions & \multicolumn{3}{c}{ Players } & \multicolumn{2}{c}{ Ratios } \\
\hline Andalusia & Under- & La & Absolut & La Liga/U- & Absolute/U- \\
Aragon & 63 & 247 & 34 & $3.9(10)$ & $0.5(14)$ \\
Asturias & 11 & 37 & 7 & $3.4(11)$ & $0.6(11)$ \\
Baleares & 18 & 101 & 19 & $5.6(4)$ & $1.1(3)$ \\
Basque Country & 16 & 38 & 3 & $2.4(17)$ & $0.2(18)$ \\
Canarias & 42 & 221 & 43 & $5.3(5)$ & $1.0(4)$ \\
Cantabria & 16 & 68 & 10 & $4.3(8)$ & $0.6(12)$ \\
Castille-La & 6 & 55 & 6 & $9.2(1)$ & $1.0(5)$ \\
Castille-Leon & 17 & 46 & 7 & $2.7(15)$ & $0.4(17)$ \\
Catalonia & 16 & 67 & 11 & $4.2(9)$ & $0.7(9)$ \\
Ceuta & 71 & 176 & 31 & $2.5(16)$ & $0.4(16)$ \\
Extremadura & 2 & 3 & 1 & $1.5(18)$ & $0.5(15)$ \\
Galicia & 4 & 36 & 10 & $9.0(2)$ & $2.5(1)$ \\
La Rioja & 15 & 69 & 10 & $4.6(6)$ & $0.7(10)$ \\
Madrid & 3 & 21 & 5 & $7.0(3)$ & $1.7(2)$ \\
Murcia & 61 & 183 & 36 & $3.0(12)$ & $0.6(13)$ \\
Navarre & 7 & 21 & 6 & $3.0(12)$ & $0.9(6)$ \\
Valencia & 18 & 77 & 15 & $4.3(7)$ & $0.8(7)$ \\
\hline Total & 40 & 118 & 28 & $3.0(14)$ & $0.7(8)$ \\
\hline
\end{tabular}

Notes: Parentheses number covering each autonomous community in the ranking.

Melilla has been eliminated for not bringing players to the selection. 
Figure 1. Ratio between number of players in La Liga (1985-2012) and 2012 population

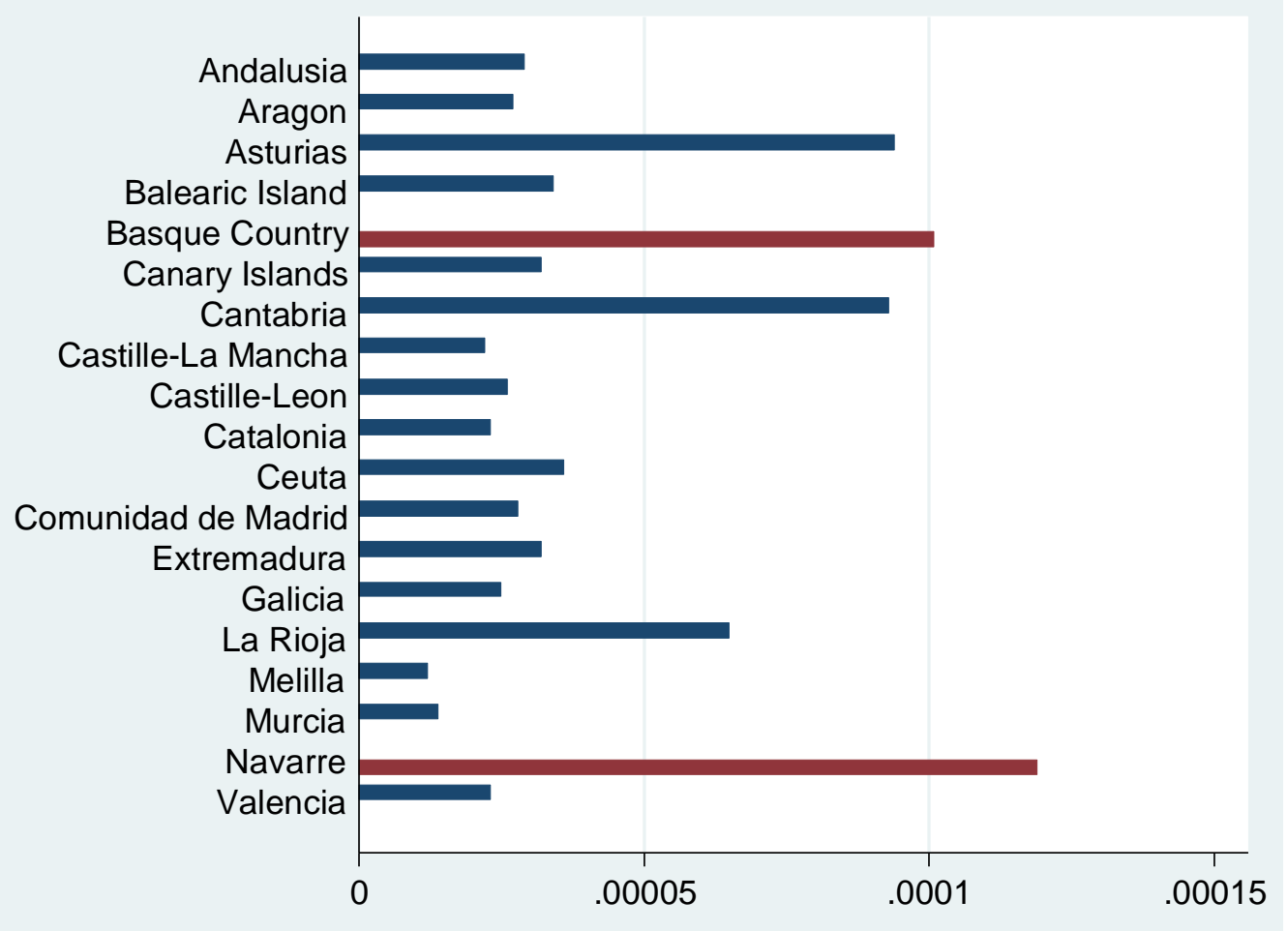


Figure 2. Ratio between the number of players in the Absolute National team (1985-2012) and 2012 population

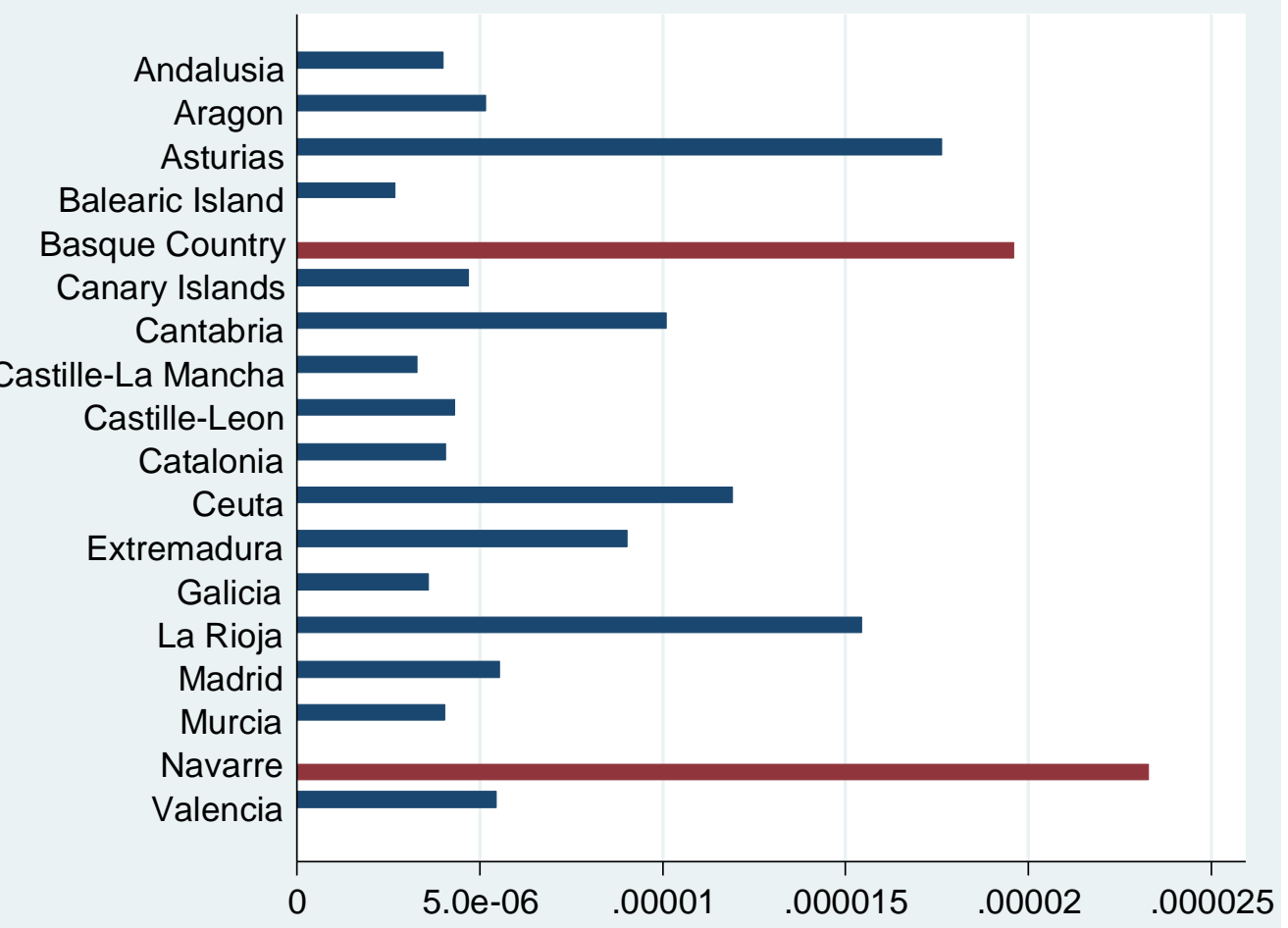


Table A1. Descriptive statistics of the players

\begin{tabular}{lcccc}
\hline Variables & Mean & Typical Deviation & Minimum & Maximum \\
\hline Minutes & 9,104 & 8,833 & 506 & 55,746 \\
Matches & 123 & 109 & 6 & 622 \\
Seasons & 6 & 4 & 1 & 20 \\
Date of birth & 1973 & 9 & 1951 & 1993 \\
Goalkeeper & $9.40 \%$ & & & \\
Defense & $38.34 \%$ & & & \\
Midfielder & $33.98 \%$ & & & \\
Forward & $18.28 \%$ & & & \\
\hline
\end{tabular}

